\title{
Teaching Design of Intercultural Discussions in College English Based on ORID Mode
}

\author{
Beili Liu \\ Beijing Information Technology College, Beijing, China \\ Email: liubl32@163.com
}

How to cite this paper: Liu, B. L. (2019) Teaching Design of Intercultural Discussions in College English Based on ORID Mode. Open Journal of Modern Linguistics, 9, 67-75.

https://doi.org/10.4236/ojml.2019.92007

Received: March 11, 2019

Accepted: April 6, 2019

Published: April 9, 2019

Copyright $\odot 2019$ by author(s) and Scientific Research Publishing Inc. This work is licensed under the Creative Commons Attribution International License (CC BY 4.0).

http://creativecommons.org/licenses/by/4.0/

\begin{abstract}
In college English courses, discussion as a way of teaching is commonly used in intercultural teaching. However, in the actual English classroom teaching, discussions often become a mere formality, and the effectiveness is limited. Based on the ORID mode, this paper focuses on the subjects of intercultural discussions and the teaching objectives, and explores the teaching design that has effective ways of intercultural discussion and creative ways of discussion grouping.
\end{abstract}

\section{Keywords}

ORID Mode, Intercultural Discussion, Teaching Design, College English

\section{Introduction}

With the further development of the teaching concept of "student-centered", students' learning through "discussion" has become an indispensable part of intercultural English teaching. Effective classroom "discussion" is not only conducive to improving students' critical thinking abilities, language expression abilities and cooperation abilities, but also gives better play to students' initiative and enthusiasm in learning, deepens students' understanding of knowledge, and promotes students' flexibility in the use of knowledge, which improves teaching effect and achieves teaching objectives.

However, in the actual intercultural English teaching in colleges, the "discussion" of students often results in "low participation", "formalization", "deviation from the theme" and other problems, resulting in "get half the result with twice the effort". It is a waste of valuable classroom time, and gets little actual effect. How to carry out "effective" discussion, so that "discussion" can give play to its due advantages, and fully serve the teaching, is an urgent practical problem to be 
solved. Based on the ORID mode of the focused conversation method, this paper discusses how to make a teaching design that can carry out "quality" intercultural discussion in college English courses.

\section{ORID Dimensions of Focused Conversation Method}

Focused conversation method is a practical method of organizing discussions and designing questions, which has been developed and perfected based on the research and observation of people's information processing features in the 40 years' work of Canadian Institute of Cultural Affairs. It is a discussion method that promotes deep thinking, promotes meaningful learning, and enhances team communication through effective questioning.

Focused conversation method includes "O-R-I-D" thinking mode in four dimensions: objective dimension, reflective dimension, interpretative dimension and decisional dimension. These four dimensions follow the internal process of human cognition (Wu \& Wu, 2014): perception-reaction-judgment-decision.

Objective dimension $(\mathrm{O})$ refers to the processing of information and sensory perception. Participants accumulate information through the subject's facts and external realities.

Reflective dimension (R) refers to the individual's reactions and associations. Participants experienced their own psychological feelings and emotional responses to the known information. Subjectivity externalizes the world while objectifying the inner world. Everyone has their own reaction in any situation, which is related to personal experience. Under a lot of circumstances, this dimension is bypassed; people can even be unaware of its existence.

Interpretive dimension (I) is about importance and meaning. Participants associate the information that they receive with their own reactions. They get associations, explore values, and discover hidden meanings.

Decisional dimension (D) focuses on solutions. Participants draw conclusions or make decisions based on the above considerations (Nelson, 2006).

\section{Previous Studies on ORID Mode}

ORID mode can be applied to the course framework, the structure of a class, and the arrangement of a specific discussion problem. This mode can provide an effective logical framework for students' thinking and help them clarify their thinking. However, there are few studies on discussions in college English teaching based on ORID mode.

Searched on the website of CNKI with the keyword "ORID mode", or "focused conversation method", 6 papers are found altogether. Narrow the search down with the keyword "English teaching", there is only one paper, which is entitled English Classroom Discussion Design Based on Focus Discussion Method (Mo, 2018). In this paper, the author argues the process of designing a general discussion in English classes based on ORID mode briefly, which is valuable to further studies on the teaching design of intercultural discussions in college English teaching. 


\section{Determining Discussion Subjects and Teaching Objectives in Intercultural Teaching}

\subsection{Focusing on the Subjects of Cultural Discussions}

A quality discussion begins with quality preparation. The first step to integrate intercultural teaching into college English course is to determine the subjects of intercultural teaching. Because most of the current college English courses focus on the English language teaching, the intercultural content is less, scattered and lack of systematicness (Zhang, 2007). The selection of intercultural subjects can be combined with each unit of the English tutorial theme, and make the overall framework design. After determining the cultural subjects which are integrated into the teaching as a whole, each cultural subject will be separately focused and the focus of discussion on each cultural subject will be determined.

Without focus, the discussion will be vague and shallow. Focused discussion topics enable participants to construct objective information more clearly, leading to deeper discussions at the level of interpretation. For example, it is too vague to discuss the topic of Chinese and foreign traffic culture, which can lead to a number of different focused discussions. The focus of discussion may be the use of daily vehicles, awareness of traffic rules, environmental protection and so on.

\subsection{Determining the Teaching Objectives of the Culture-Focused Discussions}

Teaching objectives can be divided into three parts, which are knowledge objectives, ability objectives and quality objectives. Knowledge objective refers to the cultural knowledge and understanding acquired by students after the discussion. The ability objective may be to discover the deep connotation of a certain cultural subject, the values of the target language user, the decision on how to solve the problems caused by cultural conflicts, and so on. Quality objective refers to the internal influence of the discussion process on students. For instance, it can enhance students' confidence in intercultural communication, respect for different cultures, accept cultural diversity, and enhance their sense of mission to spread Chinese culture to the world.

\section{Teaching Process of Intercultural Discussion Based on ORID Mode}

\subsection{Leading-In by Cultural Cases-Objective Dimension}

The focused conversation method suggests that discussion should be led in from an objective question about a specific object or common experience, which contains the information that students can observe. Without a concrete starting point for objectivity, discussion will be difficult. Leading in from an abstract problem leads to confusion. For instance, a focused discussion is adopted to help participants understand the differences in social behaviors between China and the United States, and understand that China is the representative of collectivism culture and the United States is the representative of individualism culture. 
Without a discussion that starts with concrete examples, the discussion will become clueless and vague.

A specific discussion can be started with a piece of news, a short story, a job $\mathrm{AD}$, or a video. In intercultural teaching, students can compare the similarities and differences between the mother tongue culture and the target language culture. Therefore, in the leading-in part, there are usually two specific examples that are closely related to life and represent different cultures respectively. Specific examples can trigger students to think deeply, and students can associate the specific information with their own experiences.

After determining the leading-in materials, teachers brainstorm and design questions according to cultural subjects and teaching objectives. Most of the problems are simple and objective. Students are required to describe images, situations, events, or moments that they feel are prominent in the given story. There is no need to do any analysis in this phase, just gather ideas and give a short description. For example, what is the main idea of the story? What are the similarities and differences between the two stories? When the students speak, teachers can write their ideas on the blackboard, so as to make the content selected from the examples visible and provide the background for the discussion. Often, recalling a specific situation can trigger more thoughts later.

In addition, students can ask questions themselves. For example, what are the three questions that you want to ask the author about his news report most? In class, students can share their questions with the group members and discuss by exploring these questions. The first method is more suitable for beginners who have just come into contact with intercultural communication, while the second method is more suitable for students who are familiar with intercultural communication.

\subsection{Accumulation of Cultural Knowledge-Objective Dimension}

In this stage, students will obtain the information of Chinese and foreign cultures in the same category as the cultural cases have been introduced in the leading-in part, and specifically understand the content of Chinese and foreign cultures of this subject to accumulate cultural knowledge. In this step, the teacher makes sure that the students have access to relevant information. One of the prerequisites for a successful discussion is that the participants have a good understanding of the issues to be discussed. Of course, full knowledge is only an ideal. However, as an ideal, it makes sense to try to ensure that every participant has the opportunity to have full access to information. Information accumulation can be obtained through teachers' explanation and peers' sharing, as well as through video, Internet and MOOCs.

\subsection{Cultural Associations and Feelings-Reflective Dimension}

Students experience their own psychological feelings and emotional responses to the given cultural knowledge. In this stage, teachers encourage students to express their true feelings about cultural information. There is no right or wrong 
response from students, and there is no wrong answer in the discussion. Teachers can set basic rules for discussion, which can make students feel at ease and ensure that the environment for discussion is safe. Everyone can actively participate in the discussion. In this way, it can arouse students' enthusiasm to speak and attract more students to participate in the discussion.

In this part of teaching, discussions should not be limited to the questions between "like" and "dislike", and the questions that can trigger students' personal association can be discussed. Questions can be asked like: What does this remind you of? Which part surprises you? What makes you happy? What makes you feel conflicted or conflicted? What impresses you most? What puzzles you most?

\subsection{Discussion on Cultural Connotation-Interpretive Dimension}

The questions discussed in the interpretive dimension are based on objective cultural information and associations or feelings acquired by students. The key question at this level is "why?". It will involve the similarities and differences of "values" between Chinese and foreign cultures. Chinese education scholar $\mathrm{Hu}$ Wenzhong (1999) pointed out: "values are the core of intercultural communication... It's the deepest part of culture... Once formed, values govern people's beliefs, attitudes, perceptions and actions and become a guide for people's actions". In this stage, students discuss values and discover the hidden meaning of cultural knowledge. For example, in Chinese and western "gift" cultures, what are the reasons for the gaps related to "gifts' prices"? What's the reason for the different times of gift checking?

In this stage, it's important to get rid of "stereotypes". Stereotypes about different cultures may exist prior to the discussion. At the same time, "ethnocentrism" should be avoided either. We should not judge other cultures by our own national values or our own standards of right and wrong.

\subsection{Improvement of Intercultural Communication Competence-Decisional Dimension}

The fourth stage of the focused conversation method is the decisional dimension. At this level, the focus of the problem is on the solution, impact, results, applications, and such. Teachers can guide students to discuss the influence and results caused by the differences between Chinese and foreign cultures who discussed, points for attention in the course of intercultural communication, and how to better spread Chinese culture and conduct intercultural communication appropriately, etc. This level of problem urges students to use the information obtained in the previous three stages of discussion to make choices and explore the application of cultural knowledge and cultural connotation in daily life.

\section{Grouping of Intercultural Discussions Based on ORID Mode}

After determining the specific stages of discussion activities in intercultural teaching, it is necessary to design the ways of grouping and discussion. Different 
ways of grouping and discussion are adopted in different discussion stages, so as to carry out intercultural discussion more effectively.

\subsection{Ways of Grouping}

There are two ways of grouping in discussions basically: class discussion and group discussion.

\subsubsection{Class Discussion}

Put the class as a group to discuss. The usual practice is for all the students to sit in a circle or $\mathrm{u}$-shape. Class-wide discussions provide opportunities for students to hear different voices in a wider context. However, due to the gushing of some people, the large-scale discussion may limit the participation of some students. In the leading-in part of intercultural teaching, the whole class can discuss together.

\subsubsection{Group Discussion}

Groups of about five are better and more effective (Stephen \& Stephen, 2011). Students can choose to group freely or teachers can assign groups. Both methods have their advantages and disadvantages.

When students freely choose groups, they tend to choose those who get along well with each other. They know each other, trust each other, which is helpful for open heart and candid communication. This way of grouping is suitable for discussing some sensitive issues of intercultural communication. The downside is that they tend to choose people who hold the similar views, thus reduces the opportunity for them to argue and appreciate different points of view, which is a valuable part of discussion.

When students are grouped by teachers, teachers can put students with different views and experiences, different personalities, different genders and different grades into one group. "Heterogeneous" groups sometimes make the discussion more challenging and critical, but the large difference between group members may also lead to the discussion turning into a quarrel. The teacher can decide the composition of the group according to the subject of the intercultural discussion or the purpose of the activity.

In addition, intra-group assignments are performed. The teacher should select the moderator and recorder according to their experience, make everyone participate actively, and make the discussion group in an organized state.

\subsection{Engagement in Creative Group Discussions}

The key to the success of intercultural teaching discussions lies in the changing pace and diversity of discussions. The teacher may carry out the group discussions creatively according to the teaching objectives and the students' situation.

\subsubsection{Relaxed Discussion Groups}

In a loose discussion group, the student group is not required to answer the re- 
served questions, and there is no pressure to submit any reports to the large group (Stephen \& Stephen, 2011). The only requirement is that the team members must concentrate on intercultural communication. They can ask questions to anyone in the group, point out the difficulties in the cultural content and their interests, and try to get to the main points of the cultural theme. It's up to the group to decide how to talk, to make sure everyone is comfortable. Relaxed discussion groups help break the ice, get to know each other, and motivate further discussion. In the link of "cultural knowledge accumulation", a loose group discussion can be adopted. However, looseness can cause discussion to degenerate into chat, and the timeliness is weak.

\subsubsection{Organized Discussion Groups}

Students usually take 10 - 15 minutes to answer questions about intercultural communication. The group's result is needed to be summarized in the large class report. The advantage of the organizational discussion is that it provides an agenda for the whole group, which is timely and can be adopted in any stage in intercultural teaching. The disadvantage is that students cannot give full play to the initiative.

\subsubsection{Student Expert Discussion}

In this way of grouping, the number of discussions is equal to the square root of the class size. For example, for a class of 25 students, there are 5 students in each group, and each group chooses a question to discuss (Stephen \& Stephen, 2011). After everyone in the group becomes an "expert", a new group will be formed, and the new group will be composed of the "expert" of each original topic. Each "expert" takes turns leading the group to discuss their own "expert" topics. The discussion ends when all the group members have mastered all of the knowledge. The discussion mode of "student expert" is applicable to the link of "cultural knowledge accumulation". This activity can give the silent students a chance to speak and strengthen their confidence.

\subsubsection{Theatrical Discussion}

Students present their discussion in the form of a theatrical performance. 6-7 students can form a group to discuss a certain cultural subject and determine their psychological feelings and emotional reactions to the culture. The group then presents their psychological feelings and emotional responses in some imaginative form of fiction, whether it is a short satirical comedy, a mock radio show, a song, a poem, or even a short story told in pantomime. This activity is suitable for the teaching link of "cultural association and feeling".

\subsubsection{Poster Discussion}

One way to avoid the tedium of a presentation is to suggest that each group write down the results of their discussion on a large piece of paper or a blackboard. Each student in the class can go back and forth in the classroom and read all the insights and compare them with their own group's. This activity is very 
attractive, easy to operate and provides different reporting methods. This method can be used in the links of "discussion on cultural connotation" and the final "decision" part in intercultural teaching.

\subsubsection{Online Discussion}

Online discussion is not limited by time and place, and student groups can discuss through information means such as "WeChat". In addition, this kind of discussion gives students time to react, reduces the anxiety of introverted students, and makes the discussion more democratic. In intercultural teaching, online discussion is mainly applicable to pre-class preview and after-class extension.

\section{Conclusion}

The teaching design of intercultural discussions in college English based on ORID mode can be basically classified into three parts: focusing the subject and determine the teaching objectives; designing the process and content of intercultural discussions; designing the form of discussions.

In college English courses, intercultural teaching should first be prepared before discussion: the overall planning of the cultural subjects of learning should be made to make intercultural teaching systematic. In addition, the focus and teaching objectives of each cultural subject are determined respectively.

In classroom teaching, based on the ORID mode, classroom discussion can be divided into five stages and four levels. That is, 1) Leading-in by cultural case-Objective dimension. The objective problem is to obtain appropriate samples of cultural information, so as to further expand the information of the cultural subject. 2) Accumulation of cultural knowledge-Objective dimension. Intercultural knowledge is acquired in this stage. 3) Cultural association and feeling-Reflective dimension. In this stage, discussions of participants' feelings and emotional reactions to the cultural subject are carried out. 4) Discussion on cultural connotation-Interpretive dimension. Participants discuss the underlying causes of cultural differences in this period. 5) Improvement of intercultural communication competence-Decisional dimension. How to apply the cultural knowledge in intercultural communication is discussed.

Furthermore, ways of grouping and forms of discussion are essential to the success of cultural discussions as well. The two basic ways of grouping are class discussion and group discussion, which have their own upsides and downsides respectively. According to different stages of discussion based on ORID mode, forms of discussion can be chosen to use flexibly and creatively, such as relaxed discussion groups, organized discussion groups, student expert discussion, theatrical discussion, poster discussion and online discussion, which can facilitate more effective and interesting intercultural discussions.

\section{Conflicts of Interest}

The author declares no conflicts of interest regarding the publication of this paper. 


\section{References}

Hu, W. Z. (1999). Introduction to Intercultural Communication (pp. 165-166). Beijing: Foreign Language Teaching and Research Press.

Mo, J. X. (2018). English Classroom Discussion Design Based on Focus Discussion. Method in Journal of Xingtai University, 9, 167-169.

Nelson, J. (2006). The Art of Focused Conversation for Schools (pp. 17-23). Translated by Tu Bin, Beijing: Educational Science Press.

Stephen, D. B., \& Stephen, P. (2011). Discussion as a Way of Teaching (pp. 85-87, p. 92). Translated by Luo Jing et al., Beijing: China Light-Industry Press.

Wu, H. P., \& Wu, H. X. (2014). Foreign Language Teaching Methods and Schools (p. 64). Beijing: Foreign Language Teaching and Research Press.

Zhang, H. L. (2007). Intercultural Approach to Foreign Language Teaching (p. 247). Shanghai: Shanghai Foreign Language Education Press. 